\title{
Statistical discrimination of climate modification by urbanization
}

\author{
A RAMACHANDRA RAO ${ }^{1}$ and SRINVAS G RAO ${ }^{2}$ \\ ${ }^{1}$ School of Civil Engineering, Purdue University, West Lafayette, Indiana \\ 4790\%, USA \\ ${ }^{2}$ Seaburn and Robertson, Inc., P. O. Box 23184, Tampa, Florida 33634, \\ USA
}

\begin{abstract}
The statistical significance of observed changes in precipitation characteristics brought about by urbanization is investigated by using several statistical tests, including bivariate $\chi^{2}, T^{2}$, likelihood ratio and conditional- $t$ tests. Annual precipitation data from a number of stations in the LaPorte, St. Louis, Tulsa and Kansas City areas are analysed and the results are presented. The nature and limitations of these tests are discussed from the view points of assumptions made in the tests and the number of observations needed.
\end{abstract}

Keywords. Climate modification; urbanization; precipitation; microclimate; statistical hydrology.

\section{Introduction}

Urbanization and industrialization have been found to modify the local climate and to cause changes in precipitation characteristics in urban areas. The micro-climate of urban areas is different from that of surrounding rural areas due to the difference in surface roughness characteristics, convection currents set up by increased heat from urban areas, increased nucleii concentration by industrial waste products and the increased humidity in cities. A comparison of several of these characteristics and their effects (Landsberg 1970) on urban climates indicate an increase in precipitation and related activity in urban areas and in areas downwind of urban centres compared to rural areas.

Previous investigations of the effects of urbanization on precipitation have indicated that the precipitation amounts and related activities in the LaPorte, St. Louis (Missouri and Illinois), and Tulsa (Oklahoma) areas have increased over the years (Changnon 1968, 1969, 1973, 1980, 1981; Huff \& Changnon 1970; Changnon et al 1977, 1979; Ackerman et al 1978). Changnon and his associates have studied the effects of urbanization on precipitation in the LaPorte area by analysing annual rainfall data from LaPorte, South Bend, Valparaiso and Ogden Dunes in Indiana. They concluded that the LaPorte area experienced large increases in annual precipitation since 1925. LaPorte is located downwind of the Gary industrial complex and Changnon attributed the large increase in precipitation at LaPorte due to increased steel production activity in the Gary area. The apparent increase in rainfall at LaPorte in comparison with rainfall in surrounding areas has been quoted 
as an example of inadvertent weather and climate modification. The percent increase in LaPorte precipitation is much larger than increases recorded in other areas which are affected by urbanization. Daily and seasonal precipitation changes in the LaPorte and St. Louis areas are also analysed by Changnon (1969), by Huff \& Changnon (1970) and by Changnon (1973). The recent results by Changnon (1981) are based on extensive collection and analysis of daily data. Several stochastic methods have also been used in the past for analysing the effects of urbanization on precipitation. These methods include the stochastic modelling approach, the theory of runs, intervention analysis and multivariate statistical tests.

In this paper several bivariate statistical tests are used to investigate the significance of changes in the mean value of annual precipitation attributed to the effects of urbanization. These tests include the bivariate $\chi^{2}, T^{2}$, likelihood-ratio tests and the conditional $t$ test. Data from two correlated stations are used in these tests. Annual precipitation data from a number of stations in the LaPorte, St. Louis, Tulsa and Kansas City areas are analysed and tested. These statistical tests have been used for analysing the effect of induced weather modification on precipitation and runoff by Markovic (1966) and for other applications in science and engineering. In these tests, data from two stations, one at which a relatively large change has been observed and the other at which there is little or no change are used to maximize the information available to make inferences about the change in mean at the first station. These bivariate tests are more reliable than univariate tests such as the conventional $u$ - or $t$ tests which use data from a single station only. The results of bivariate tests are, however, reliable when the data from two stations are highly correlated.

Although several of the statistical tests used in the present study have been used by others also, information about their comparative performance is not readily available. These tests are used in the present study to bring out the differences in the inferences resulting from different tests. These differences in results from different tests are also due to the small number of available observations, a common occurrence in hydrology.

In view of these problems associated with using statistical tests to investigate the climate modification, especially with small samples, the conclusions presented in this paper are tentative. However, when the conclusions from all the tests are the same, they can be accepted with greater confidence than when the results from different tests are different.

It must be noted that no attempt is made in this paper to relate the changes in the precipitation at a station to any climatic factor or degree of urbanization. Such studies have been reported by other investigators (Landsberg 1970; Changnon 1969, 1981; Changnon et al 1977, 1979; Ackerman et al 1978) with the conclusion that precipitation in or downwind of urban areas in affected by urbanization through changes in climate. In this study, the precipitation data from urban areas are analysed using statistical tests to determine the statistical significance of changes in their mean values which are attributed to urbanization.

This paper is organized as follows. Some elementary analysis of the data used in the study are discussed in $\S 2$. The statistical tests are discussed in $\S 3$ along with results from them. A discussion and a set of conclusions are given in $\S 4$.

\section{Elementary analysis of data}

Annual precipitation data from several stations in the LaPorte, St. Louis, Tulsa and 


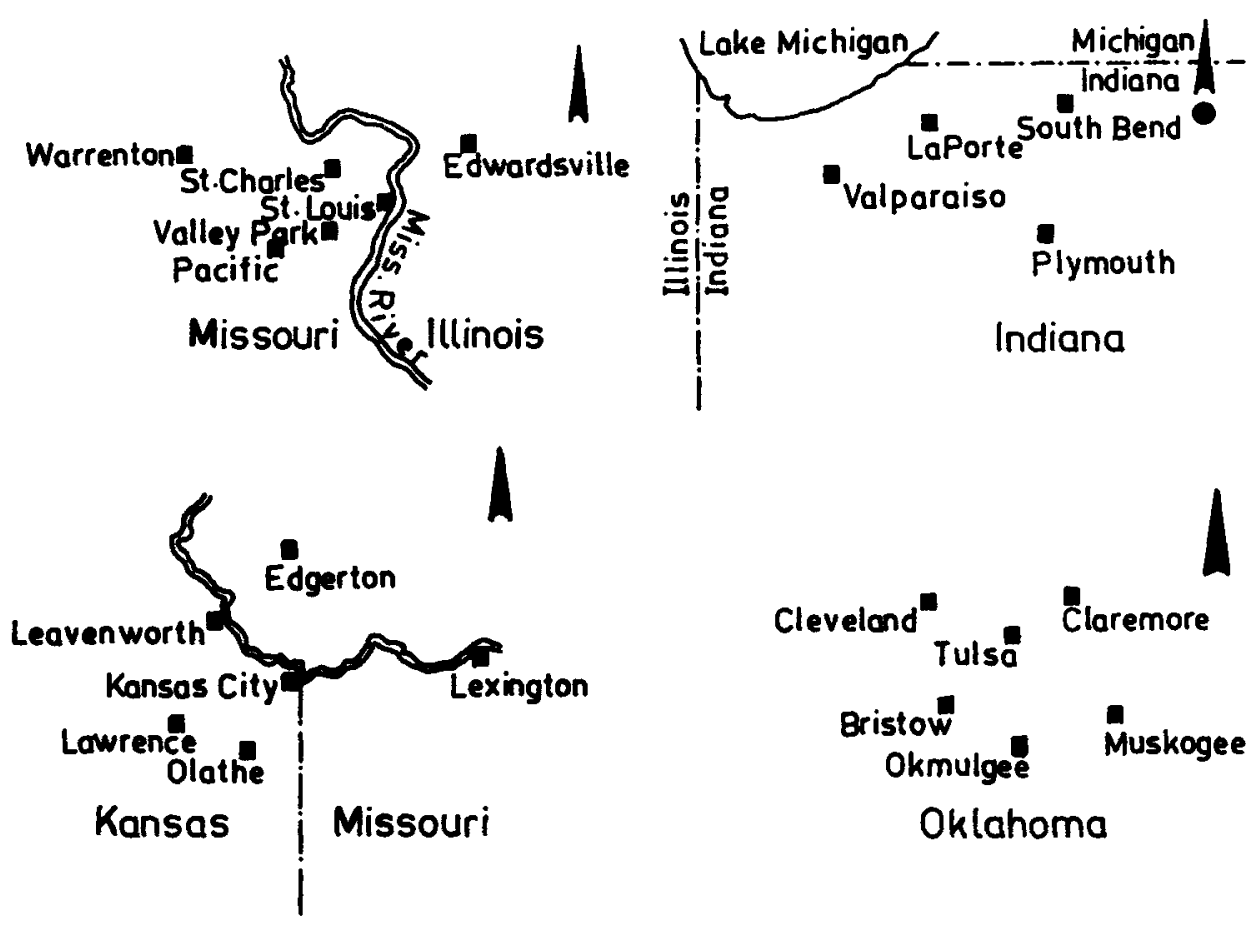

Figure 1. Location of stations.

Kansas City areas are used in this study (figure 1). These stations are listed in table 1. The approximate time at which precipitation characteristics have changed due to urbanization need to be specified in the methods used herein and this is determined for each station by using a mass curve (see figure 2 for an example); double mass curve analysis; examination of averages of split samples of data and the break points which are summarized in table 1 for each urban area. The precipitation data before the mean value has changed are called the unaffected period data and those from the period after, the affected period data (see figure 2 for an example).

The elementary statistics of observed annual precipitation are given in table 1 for the affected, unaffected and entire periods. Also shown in this table are the percentage changes in the mean precipitation between the two periods, namely the affected and unaffected periods. The percentage change is within $\pm 10 \%$ for all stations except for LaPorte for which it is about $+21 \%$, thereby indicating a substantial increase in precipitation at LaPorte. In some cases the change in precipitation mean values are well within one standard deviation of the unaffected period data, thereby indicating that the observed change for these cases may be statistically insignificant.

Examples of histograms of annual data are shown in figure 2. These histograms are rough approximations to the probability distribution of annual precipitation. The frequency distribution of precipitation, even in stations which are close to each other show very different characteristics. The $\chi^{2}$ goodness of fit test results indicate that these data may be considered to be approximately normally distributed (table 2). Examples of correlograms and power spectra (with \pm 2 standard errors) of annual data are shown in figure 3. Several tests including the Portmanteau lack of fit test, Anderson's test and cummulative periodogram test were performed. These tests 
Table 1. Elementary statistics of precipitation data used in the study

\begin{tabular}{|c|c|c|c|c|c|c|c|c|c|c|c|c|c|}
\hline \multirow[b]{2}{*}{ Station } & \multirow{2}{*}{$\begin{array}{l}\text { Begin- } \\
\text { ing } \\
\text { year }\end{array}$} & \multirow{2}{*}{$\begin{array}{c}\text { Ending } \\
\text { year }\end{array}$} & \multirow[b]{2}{*}{$\begin{array}{l}\text { Break } \\
\text { point }\end{array}$} & \multicolumn{3}{|c|}{ Observations } & \multicolumn{2}{|c|}{ Unaffected } & \multicolumn{2}{|c|}{ Affected } & \multicolumn{2}{|c|}{ Entire } & \multirow{2}{*}{$\begin{array}{c}\% \\
\text { Change } \\
\text { in mean }\end{array}$} \\
\hline & & & & $\begin{array}{l}\text { Unaf- } \\
\text { fected }\end{array}$ & $\begin{array}{l}\text { Affe- } \\
\text { cted }\end{array}$ & Entire & Mean & SD & Mean & SD & Mean & SD & \\
\hline LAP & 1915 & 1968 & 1929 & 14 & 40 & 54 & 36.90 & $5 \cdot 800$ & 44.59 & 8.085 & $42 \cdot 60$ & $8 \cdot 17$ & 20.84 \\
\hline SB & 1915 & 1968 & 1929 & 14 & 40 & 54 & 32.89 & $5 \cdot 008$ & $35 \cdot 88$ & $5 \cdot 621$ & $35 \cdot 11$ & $5 \cdot 53$ & $9 \cdot 09$ \\
\hline PLY & 1915 & 1968 & 1929 & 14 & 40 & 54 & 34.82 & 6.284 & $36 \cdot 12$ & 5.897 & $35 \cdot 78$ & 5.95 & 3.73 \\
\hline VALP & 1915 & 1968 & 1929 & 14 & 40 & 54 & 37.04 & 6.045 & $37 \cdot 67$ & $5 \cdot 205$ & 37.50 & 5.89 & $1 \cdot 70$ \\
\hline ST LS & 1916 & 1970 & 1941 & 25 & 30 & 55 & 34.66 & 7.532 & $36 \cdot 64$ & $8 \cdot 670$ & $35 \cdot 74$ & 808 & $5 \cdot 71$ \\
\hline EDW & 1916 & 1970 & 1941 & 25 & 30 & 55 & 37.85 & $7 \cdot 128$ & $40-46$ & $7 \cdot 827$ & $39 \cdot 27$ & $7 \cdot 49$ & 6.90 \\
\hline VALL & 1916 & 1970 & 1941 & 25 & 30 & 55 & $36 \cdot 57$ & $7 \cdot 212$ & $38 \cdot 20$ & 8.093 & $37 \cdot 46$ & $7 \cdot 61$ & $4 \cdot 46$ \\
\hline WAR & 1916 & 1970 & 1941 & 25 & 30 & 55 & 37.93 & $7 \cdot 557$ & 34.81 & $6 \cdot 712$ & $37 \cdot 75$ & 6.98 & $-8 \cdot 23$ \\
\hline ST CH & 1916 & 1970 & 1941 & 25 & 30 & 55 & 37.60 & 6.570 & 36.64 & 6.794 & 35.81 & 6.63 & -2.55 \\
\hline KAN & 1906 & 1970 & 1931 & 25 & 40 & 65 & 37.02 & 5.030 & $35 \cdot 33$ & $8 \cdot 195$ & 36.00 & $7 \cdot 18$ & $-4 \cdot 56$ \\
\hline EDG & 1920 & 1970 & 1931 & 12 & 40 & 51 & 31.66 & $5 \cdot 240$ & $32 \cdot 67$ & 10.770 & 32.45 & 9.85 & 3.19 \\
\hline LEX & 1906 & 1970 & 1931 & 25 & 40 & 65 & 38.02 & $8 \cdot 127$ & 37.67 & $9 \cdot 922$ & 37.80 & 9.02 & -0.92 \\
\hline OLA & 1906 & 1970 & 1931 & 25 & 40 & 65 & $35 \cdot 64$ & 6.664 & 36.83 & 9.358 & $36 \cdot 38$ & $8 \cdot 32$ & $3 \cdot 34$ \\
\hline LAW & 1906 & 1970 & 1931 & 25 & 40 & 65 & 36.07 & $7 \cdot 210$ & $36 \cdot 00$ & 9.072 & $36 \cdot 03$ & $8 \cdot 17$ & -0.19 \\
\hline LEA & 1906 & 1970 & 1931 & 25 & 40 & 65 & 34.47 & $5 \cdot 160$ & 36.06 & 8.898 & $35 \cdot 45$ & $7 \cdot 54$ & 4.61 \\
\hline TULS & 1916 & 1970 & 1931 & 15 & 40 & 55 & $40-21$ & 8.538 & $37 \cdot 61$ & 8.557 & $38 \cdot 34$ & $8 \cdot 28$ & -6.47 \\
\hline CLA & 1916 & 1970 & 1931 & 15 & 40 & 55 & $40-03$ & $7 \cdot 729$ & $37 \cdot 11$ & $8 \cdot 769$ & 37.91 & 8.45 & -7.29 \\
\hline MUSK & 1916 & 1970 & 1931 & 15 & 40 & 55 & $41 \cdot 74$ & $7 \cdot 434$ & $41 \cdot 50$ & $10-060$ & $41 \cdot 57$ & $9 \cdot 27$ & -0.57 \\
\hline CLE & 1916 & 1970 & 1931 & 15 & 40 & 55 & 36.87 & $8 \cdot 103$ & $35 \cdot 12$ & 9.424 & $35 \cdot 60$ & 8.96 & $-4 \cdot 75$ \\
\hline
\end{tabular}

Abbreviations - LAP: LaPorte; SB: South Bend; PLY: Plymouth; VALP: Valparaiso; ST LS: St. Louis; EDW: Edwardsville; VALL: Valley Park; WAR: Warrenton; ST CH: St. Charles; KAN: Kansas City; EDG: Edgerton; LEX: Lexington; OLA: Olathe; LAW: Lawrence; LEA: Leavenworth; TULS: Tulsa; CLA: Claremore; MUSK: Muskogee; CLE: Cleveland.

$\%$ Change-(affected period mean-unaffected period mean)/unaffected period mean.

Mean and standard deviation (SD) are in inches $(1$ in. $=2.54 \mathrm{~cm})$.

indicate that the data from each station may be considered to be uncorrelated. Details of these tests are found in Rao \& Rao (1974).

\section{The bivariate statistical tests}

Several bivariate statistical tests are used to detect the significance of observed changes in precipitation at a station. The basic assumption in these tests is that the precipitation sequence is identically and independently distributed (i.i.d.) with normal distribution. In these tests, data from a station (first station or affected station) in which a change in the mean value is suspected is used along with the data from a neighbouring station (second station or unaffected station) in which no significant change in mean has occurred to test for the significance of increase in the mean annual precipitation in the first station. Consequently, in these tests, four sets of data, two from the affected and unaffected periods from the first station and the corresponding two sets from the second station are used. These statistical tests are discussed in detail in many textbooks, such as those by Brownlee (1965), Mood \& Graybill (1963), and others. Consequently, discussion of the details of the tests is kept to a minimum here.

The null and alternate hypotheses for these tests are as follows:

$H_{0}$ : There is no increase in the precipitation mean value at the first station in the affected period. 

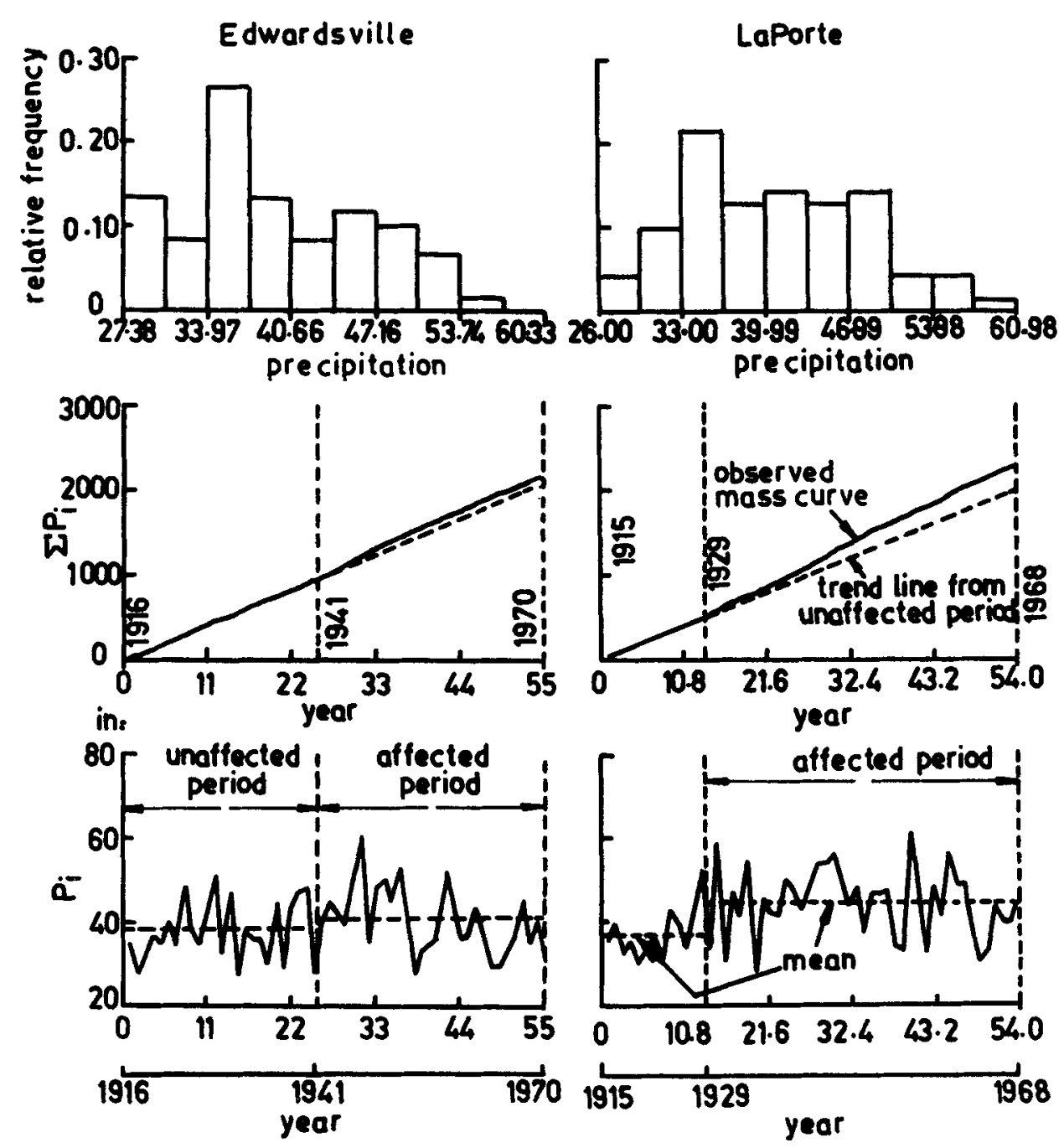

Figure 2. Typical histograms and mass curves.

$H_{a}$ : There is an increase in the precipitation mean value at the first station in the affected period.

A $5 \%$ significance level is used in all the tests. The following notation is used in the discussion of these tests. Let $P_{1 u_{i}}$ and $P_{1 a_{j}}(i=1,2, \ldots, m ; j=1,2, \ldots, n)$ be the annual precipitation at the first station in the unaffected and affected periods, and let $P_{2 u_{i}}$ and $P_{2 a_{j}}$ denote the corresponding values at the second station. Let $\mu_{1}$ and $\sigma_{1}^{2}$ be the population mean and variance for both the unaffected and affected periods for data from the first station under the assumption that there is no change in the precipitation characteristics at that station. Let $\mu_{2}$ and $\sigma_{2}^{2}$ indicate the population mean and variance at the second station. The estimates of unaffected and affected period mean and variance at the first station are respectively $\hat{\mu}_{1 u}, \hat{\mu}_{1 a}$ and $\hat{\sigma}_{1 u}^{2}, \hat{\sigma}_{1 a}^{2}$. The estimates of unaffected and affected period precipitation means at the second station are denoted by $\hat{\mu}_{2 u}$ and $\hat{\mu}_{2 a}$ and the corresponding variances by $\hat{\sigma}_{2 u}^{2}$ and $\hat{\sigma}_{2 a}^{2}$. As the data from the affected and unaffected stations should chronologically 
Table 2. Chi-square test for testing the normality of annual data.

\begin{tabular}{lrccc}
\hline Station & $\begin{array}{c}\text { Computed } \\
\chi_{0.05}^{2}\end{array}$ & $\begin{array}{c}\text { Critical } \\
\chi_{0.05}^{2}\end{array}$ & $\begin{array}{c}\text { Degrees of } \\
\text { freedom }\end{array}$ & Decision* \\
\hline LAP & 0.835 & 12.59 & 6 & A \\
SB & 3.296 & 12.59 & 6 & A \\
PLY & 0.926 & 12.59 & 6 & A \\
VALP & 5.874 & 12.59 & 6 & A \\
ST LS & 6.299 & 12.59 & 6 & A \\
EDW & 10.416 & 12.59 & 6 & A \\
VALL & 2.033 & 11.07 & 5 & A \\
WAR & 4.537 & 14.07 & 7 & A \\
ST CH & $2 \cdot 589$ & 12.59 & 6 & A \\
KAN & 2.611 & 12.59 & 6 & A \\
LEX & 1.420 & 12.59 & 6 & A \\
OLA & 4.537 & 12.59 & 6 & A \\
LAW & 1.839 & 12.59 & 6 & A \\
LEA & 1.440 & 12.59 & 6 & A \\
TULS & 8.190 & 12.59 & 6 & A \\
CLA & 10.231 & 12.59 & 6 & A \\
MUSK & 8.252 & 12.59 & 6 & A \\
CLE & 12.491 & 14.07 & 7 & \\
\hline
\end{tabular}

*A-accept the hypothesis that the data are normally distributed. Abbreviations as in table 1.

correspond to each other, the same number of observations from the affected and unaffected periods are used in these tests. Details of the annual data used for the bivariate tests are given in table 1. Two criteria are used in the selection of "unaffected" stations. The observed change in the mean in the unaffected station should be relatively small. Secondly, data from unaffected and affected stations must be as highly correlated as possible. The various statistics are computed as below:
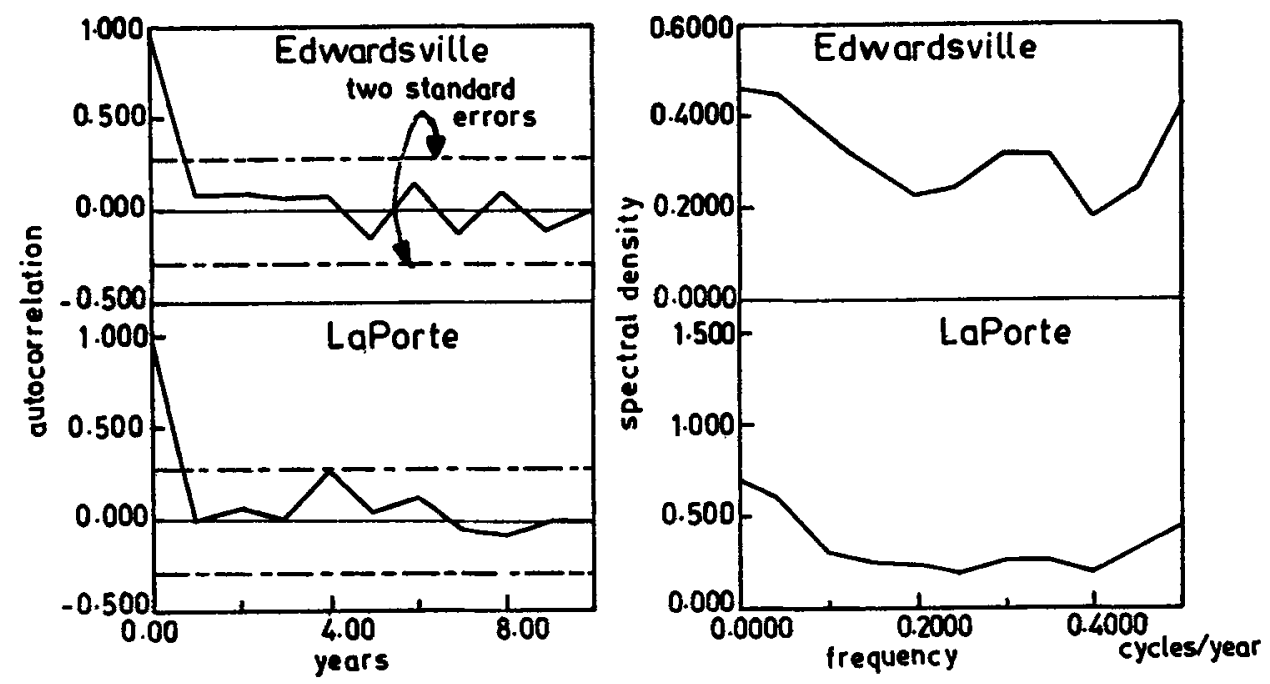

Figure 3. Correlograms and power spectral density of data. 


$$
\begin{array}{ll}
\hat{\mu}_{1 u}=(1 / m) \sum_{i=1}^{m} P_{1 u_{i}} ; & \hat{\mu}_{1 a}=(1 / n) \sum_{j=1}^{n} P_{1 a_{j}} ; \\
\hat{\mu}_{2 u}=(1 / m) \sum_{i=1}^{m} P_{2 u_{i}} ; & \hat{\mu}_{2 a}=(1 / n) \sum_{j=1}^{n} P_{2 a_{j}} ; \\
\hat{\sigma}_{1 u}=(1 / m) \sum_{i=1}^{m}\left(P_{1 u_{i}}-\hat{\mu}_{1 u}\right)^{2} ; & \hat{\sigma}_{1 a}=(1 / n) \sum_{j=1}^{n}\left(P_{1 a_{j}}-\hat{\mu}_{1 a}\right)^{2} ; \\
\hat{\sigma}_{2 u}=(1 / m) \sum_{i=1}^{m}\left(P_{2 u_{i}}-\hat{\mu}_{2 u}\right)^{2} ; & \hat{\sigma}_{2 a}=(1 / n) \sum_{j=1}^{n}\left(P_{2 a_{j}}-\hat{\mu}_{2 a}\right)^{2} .
\end{array}
$$

The unaffected and affected period sample correlation coefficients between stations 1 and 2 are denoted by $\hat{\rho}_{u}$ and $\hat{\rho}_{a}$ and the population correlation coefficient by $\rho$.

$$
\begin{aligned}
& \hat{\rho}_{u}=\left(\sum_{i=1}^{m} P_{1 u_{i}} P_{2 u_{i}}-m \hat{\mu}_{1 u} \hat{\mu}_{2 u}\right) / m \hat{\sigma}_{1 u} \hat{\sigma}_{2 u} ; \\
& \hat{\rho}_{a}=\left(\sum_{i=1}^{n} P_{1 a_{i}} P_{2 a_{i}}-n \hat{\mu}_{1 a} \hat{\mu}_{2 a}\right) / n \hat{\sigma}_{1 a} \hat{\sigma}_{2 a} .
\end{aligned}
$$

(a) The $\chi^{2}$ test

In this test, the data from the affected (station 1) and unaffected (station 2) stations are assumed to be highly correlated and bivariate normally distributed. Furthermore, the population parameters are assumed to be known.

The joint distribution of the affected period sample means from stations 1 and 2 , expressed as a bivariate normal distribution, forms the basis of the $\chi^{2}$ test. Recalling that $n$ affected period observations are available, $\left(P_{1 a_{j}}, P_{2 a_{j}}, j=1,2, \ldots, n\right)$ the bivariate normal distribution of the affected period means may be written as in (6), where $K$ is a constant associated with the bivariate normal distribution with parameters $\mu_{1}, \mu_{2}, \sigma_{1}^{2} / n, \sigma_{2}^{2} / m$ and $\rho$.

$$
\begin{aligned}
f\left(\hat{\mu}_{1 a}, \hat{\mu}_{2 a}, \mu_{1}, \mu_{2}, \sigma_{1}^{2}, \sigma_{2}^{2}, \rho\right)= & K \exp \left\{[ - n / 2 ( 1 - \dot { \rho } _ { u } ^ { 2 } ) ] \left\{\left[\left(\hat{\mu}_{1 a}-\mu_{1}\right) / \sigma_{1}\right]^{2}-\right.\right. \\
& -2 \rho_{u}\left[\left(\hat{\mu}_{1 a}-\hat{\mu}_{1}\right) / \sigma_{1}\right]\left[\left(\hat{\mu}_{2 a}-\mu_{2}\right) / \sigma_{2}\right]+ \\
& \left.\left.+\left[\left(\hat{\mu}_{2 a}-\mu_{2}\right) / \sigma_{2}\right]^{2}\right\}\right\}
\end{aligned}
$$

The exponential part of (6) is $\chi^{2}$-distributed with two degrees of freedom as in (7) (Hald 1952),

$$
\begin{aligned}
\chi_{0}^{2}= & {\left[n /\left(1-\rho_{u}^{2}\right)\right]\left\{\left[\left(\hat{\mu}_{1 a}-\mu_{1}\right) / \sigma_{1}\right]^{2}-2 \rho_{u}\left[\left(\hat{\mu}_{1 a}-\mu_{1}\right) / \sigma_{1}\right] \times\right.} \\
& \left.\times\left[\left(\hat{\mu}_{2 a}-\mu_{2}\right) / \sigma_{2}\right]+\left[\left(\hat{\mu}_{2 a}-\mu_{2}\right) / \sigma_{2}\right]^{2}\right\} \approx \chi^{2}(2)
\end{aligned}
$$

For a given bivariate population, with $\chi^{2}(2)$ as a constant, (7) represents the equation of the ellipse of the distribution surface in the $\left(P_{1}, P_{2}\right)$ plane corresponding to the joint density function of sample means given in (6). The $\chi^{2}(2)$ value may be specified at any desired confidence probability level $1-\alpha$. Consequently, the probability of the observed point $\left(\hat{\mu}_{1 a}, \hat{\mu}_{2 a}\right)$ lying within such a contour ellipse is given by 


$$
\begin{gathered}
\operatorname{prob}\left\{[ n / ( 1 - \rho _ { u } ^ { 2 } ) ] \left\{\left[\left(\hat{\mu}_{1 a}-\mu_{1}\right) / \sigma_{1}\right]^{2}-2 \rho\left[\left(\hat{\mu}_{1 a}-\mu_{1}\right) / \sigma_{1}\right] \times\right.\right. \\
\left.\left.\times\left[\left(\hat{\mu}_{2 a}-\mu_{2}\right) / \sigma_{2}\right]+\left[\left(\hat{\mu}_{2 a}-\mu_{2}\right) / \sigma_{2}\right]^{2}\right\}\right\} \\
=\chi_{0}^{2} \leqslant \chi_{1-\alpha}^{2}(2)=\int_{0}^{\chi_{1-\alpha}^{2}(2)} f\left(g_{1}\right) \mathrm{d} g_{1}=1-\alpha,
\end{gathered}
$$

in which $f\left(g_{1}\right)$ is the probability density function of the chi-square variate with two degrees of freedom.

The equation for the confidence ellipse given in (8) may be simplified by using the orthogonal transformation of variables $P_{1}$ and $P_{2}(9)$, which respectively represent the annual precipitation series at the first and second stations, by the new variables $q_{1}$ and $q_{2}$.

$$
\begin{aligned}
& q_{1}=\left(P_{1}-\mu_{1}\right) \cos \zeta+\left(P_{2}-\mu_{2}\right) \sin \zeta, \\
& q_{2}=\left(P_{2}-\mu_{2}\right) \cos \zeta-\left(P_{1}-\mu_{1}\right) \sin \zeta .
\end{aligned}
$$

The equation of the contour ellipse in terms of the variables $q_{1}$ and $q_{2}$ is given by (10). The variances $\sigma_{q_{1}}$ and $\sigma_{q_{2}}$ of $q_{1}$ and $q_{2}$ are determined by the relationships in (11) and the angle of rotation $\zeta$ with the horizontal axis by (12).

$$
\begin{aligned}
& \left(q_{1} / \sigma_{q_{1}}\right)^{2}+\left(q_{2} / \sigma_{q_{2}}\right)^{2}=\chi_{1-\alpha}(2), \\
& \left(\sigma_{q_{1}}+\sigma_{q_{2}}\right)^{2}=\sigma_{1}^{2}+\sigma_{2}^{2}+2 \sigma_{1} \sigma_{2}\left(1-\rho^{2}\right)^{1 / 2} \text {, } \\
& \left(\sigma_{q_{1}}-\sigma_{q_{2}}\right)^{2}=\sigma_{1}^{2}+\sigma_{2}^{2}-2 \sigma_{1} \sigma_{2}\left(1-\rho^{2}\right)^{1 / 2} \text {, } \\
& \tan 2 \zeta\left[\begin{array}{l}
=\left(2 \rho \sigma_{1} \sigma_{2}\right) /\left(\sigma_{1}^{2}-\sigma_{2}^{2}\right) ; \quad \sigma_{1} \neq \sigma_{2}, \\
=\infty ; \quad \zeta=\pi / 4 ; \quad \sigma_{1}=\sigma_{2} .
\end{array}\right.
\end{aligned}
$$

The centre of the confidence ellipse is at the point $\left(P_{1}, P_{2}\right)=\left(\mu_{1}, \mu_{2}\right)$, and the lengths of the semi-major and -minor axes are given by

$$
\begin{aligned}
& q_{1,0}=\sigma_{q_{1}} \chi_{1-\alpha}(2), \\
& q_{2,0}=\sigma_{q_{2}} \chi_{1-\alpha}(2) .
\end{aligned}
$$

The test of significance may be conducted by constructing the confidence ellipse given in $(10)$ in the $\left(P_{1}, P_{2}\right)$ plane and by plotting the estimate $\left(\hat{\mu}_{1 a}, \hat{\mu}_{2 a}\right)$. If the observed point $\left(\hat{\mu}_{1 a}, \hat{\mu}_{2 a}\right)$ falls within the confidence ellipse, then it is concluded that there is no significant change in the precipitation mean in the affected period at the first station. If the point $\left(\hat{\mu}_{1 a}, \hat{\mu}_{2 a}\right)$ is to right of the major axis and outside the confidence ellipse then the mean annual rainfall at the first station during the affected period is significantly (at the level $1-\alpha$ ) larger than the corresponding value for the unaffected period.

An alternate method to test the significance of change in means is by computing the statistic $\chi_{0}^{2}$ of $(7)$. If $\chi_{0}^{2} \leqslant \chi_{1-2 \alpha}^{2}(2)$ then the hypothesis that $\hat{\mu}_{1 a}$ is significantly larger than $\hat{\mu}_{1 u}$ is rejected at the level $1-2 \alpha$. Otherwise, it is accepted at the same significance level. Because this is a one-sided test, $2 \alpha$ rather than $\alpha$ is used in this test.

The correlation characteristics and bivariate normality of the data are tested and some of the stations in each data set are found to be highly correlated and bivariate normally distributed. The correlation coefficients between stations are summarized in table 3. 
Table 3. Results from the $\chi^{2}$-Test.

\begin{tabular}{|c|c|c|c|c|c|}
\hline Station 1 & Station 2 & $\begin{array}{c}\text { Correlation } \\
\text { coefficient }\end{array}$ & $\begin{array}{c}\text { Test } \\
\chi_{0}^{2}\end{array}$ & $\begin{array}{c}\text { Critical } \\
\text { value }\end{array}$ & Decision \\
\hline LAP & SB & 0.893 & $325 \cdot 65$ & $4 \cdot 61$ & $\mathbf{R}$ \\
\hline LAP & VALP & 0.649 & $106 \cdot 77$ & $4 \cdot 61$ & $\mathbf{R}$ \\
\hline LAP & PLY & 0.806 & $103 \cdot 21$ & $4 \cdot 60$ & $\mathbf{R}$ \\
\hline ST LS & WAR & 0.753 & 6.37 & $4 \cdot 60$ & $\mathbf{R}$ \\
\hline ST LS & VALL & 0.899 & $6 \cdot 16$ & $4 \cdot 60$ & $\mathbf{R}$ \\
\hline ST LS & ST CH & 0.872 & $9 \cdot 12$ & $4 \cdot 60$ & $\mathbf{R}$ \\
\hline EDW & WAR & 0.788 & $13 \cdot 31$ & $4 \cdot 60$ & $\mathbf{R}$ \\
\hline EDW & VALL & 0.839 & 4.86 & $4 \cdot 60$ & $\mathbf{R}$ \\
\hline EDW & ST CH & 0.823 & $4 \cdot 24$ & $4 \cdot 60$ & A \\
\hline KAN & LEX & 0.776 & $10 \cdot 36$ & $4 \cdot 60$ & $\mathbf{R}$ \\
\hline KAN & LAW & 0.673 & $8 \cdot 75$ & $4 \cdot 60$ & $\mathbf{R}$ \\
\hline KAN & EDG & 0.571 & 3.61 & $4 \cdot 60$ & A \\
\hline KAN & OLA & 0.736 & $22 \cdot 15$ & $4 \cdot 60$ & $\mathbf{R}$ \\
\hline LEAV & LEX & 0.570 & 6.89 & $4 \cdot 60$ & $\mathbf{R}$ \\
\hline LEAV & LAW & 0.660 & $7 \cdot 33$ & $4 \cdot 60$ & $\mathbf{R}$ \\
\hline LEAV & EDG & 0.760 & $12 \cdot 53$ & $4 \cdot 60$ & $\mathbf{R}$ \\
\hline LEAV & OLA & 0.574 & 3.95 & $4 \cdot 60$ & A \\
\hline TULS & CLA & 0.907 & $6 \cdot 36$ & $4 \cdot 60$ & $\mathbf{R}$ \\
\hline TULS & CLE & 0.714 & 9.83 & $4 \cdot 60$ & $\mathbf{R}$ \\
\hline TULS & MUS & 0.800 & $9 \cdot 83$ & $4 \cdot 60$ & $\mathbf{R}$ \\
\hline VALL & WAR & 0.858 & $10 \cdot 63$ & $4 \cdot 60$ & $\mathbf{R}$ \\
\hline VALL & ST CH & 0.869 & 3.45 & $4 \cdot 60$ & $\mathbf{A}$ \\
\hline
\end{tabular}

A-accept the null hypothesis that there is no change in the mean;

$\mathbf{R}$-reject the null hypothesis that there is no change in the mean.

Abbreviations as in table 1.

The confidence ellipse at a significance level $\alpha(=5 \%)$ is constructed as follows. The centre of the ellipse and the lengths of semi-major and -minor axes are computed by using (13) for any set of bivariate data. The angle of the major axis of the ellipse with the horizontal axes is determined by using (12). The ellipse is then constructed on the $P_{1}-P_{2}$ plane where $P_{1}$ and $P_{2}$ are precipitation values at the affected and unaffected stations respectively. The observed point $\left(\hat{\mu}_{1 a}, \hat{\mu}_{2 a}\right)$ is located on the same plot. An example of the graphical procedure is shown in figure 4. As seen from the figure, it can be concluded that LaPorte has experienced significant increase in precipitation. Similar results for other stations indicate significant increase at Leavenworth, and insignificant changes at all other stations (Rao \& Rao 1974).

The results of the alternative $\chi^{2}$ test and the decisions are given in table 3 . The null hypothesis is rejected for LaPorte data for all combinations of the unaffected stations. The null hypothesis is rejected for Valley Park with Warrenton whereas it is accepted for Valley Park with St. Charles. Since Valley Park data are better correlated with St. Charles than Warrenton data (with correlation coefficients 0.869 and 0.858 , respectively, as shown in table 2), the mean precipitation at Valley Park may be concluded to have increased. The results from Edwardsville data indicate that there has been a change in Edwardsville precipitation when Warrenton and Valley Park data are considered as unaffected data but the hypothesis of no change must be accepted for the Edwardsville-St. Charles combination. Since Edwardsville data are best correlated with those from Valley Park, it is concluded that there is a change in the mean value at Edwardsville. The null hypothesis is again rejected for 


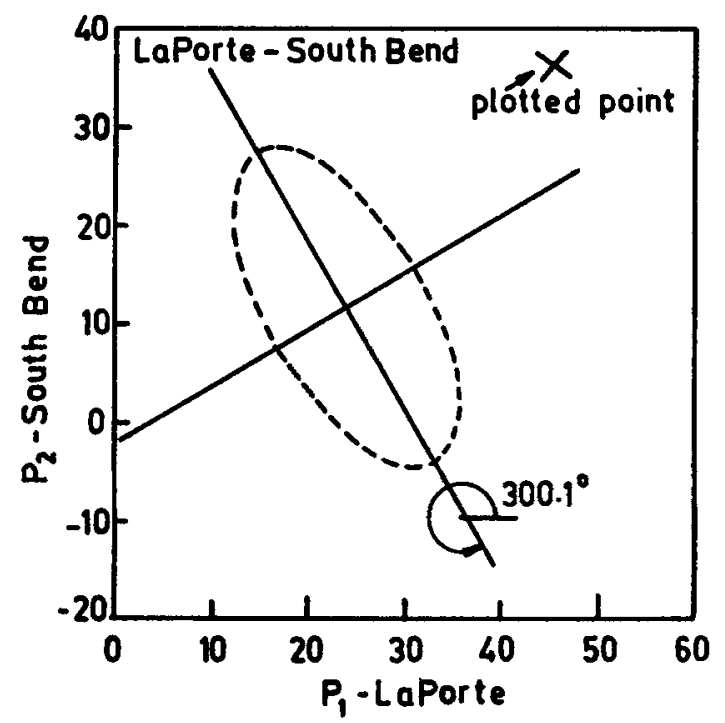

Figure 4. Typical results from the $\chi^{2}$-test.

St. Louis data considered with data from other unaffected stations, all of which are highly correlated with St. Louis data.

Similarly, the null hypothesis is rejected for Leavenworth data with Lexington, Lawrence and Edgerton as unaffected stations but accepted for Leavenworth-Olathe data. Since the data from Leavenworth and Olathe are poorly correlated, this result for Leavenworth-Olathe is not accepted. The data from Kansas City indicate a change in mean value with Lexington, Lawrence and Olathe as unaffected stations whereas the Kansas-Edgerton data does not indicate any such change. The change in mean value is significant for Tulsa data with Claremore and Muskogee data whereas it is not significant with Cleveland data. Since the data from Tulsa is better correlated with Claremore and Muskogee than Cleveland, it is concluded that there is a change in the mean value at Tulsa.

In conclusion, the graphical $\chi^{2}$-test indicates a change in mean value for data from LaPorte and Leavenworth. The alternate $\chi^{2}$-test indicates that the change in mean is significant for data from LaPorte, St. Louis, Valley Park, Edwardsville, Kansas, Leavenworth and Tulsa. These conclusions are based on using data sets from stations which are best correlated with affected stations. The alternate $\chi^{2}$-test is more sensitive in detecting changes than the graphical method.

\section{(b) The $T^{2}$ test}

The $T^{2}$ test is similar to the $\chi^{2}$ test discussed above with the exception that in the $T^{2}$ test the population parameters are assumed to be unknown. Consequently, the test statistic is $F$-distributed and not $\chi^{2}$-distributed as in the previous test. Depending on the covariance estimators, three forms of the $T^{2}$-test are available and these are discussed below.

The null and alternate hypotheses for this test are as follows. Let $\delta_{a}$ and $\delta_{u}$ be the unknown values of change in precipitation means at stations 1 and 2 , respectively. Then:

$$
H_{0}: \quad \delta_{a}=0, \quad H_{a}: \quad \delta_{a} \neq 0 .
$$


$T^{2}$ test no. 1 -test using combined estimators: The combined correlation coefficient $\hat{\rho}_{c}$ for the data from the first and second stations is given in (14), where $\hat{\sigma}_{1 c}$ and $\hat{\sigma}_{2 c}$ are the combined (pooled) standard deviations of data at stations 1 and 2 .

$$
\hat{\rho}_{c}=\left(m \hat{\rho}_{u} \hat{\sigma}_{1 u} \hat{\sigma}_{2 u}+n \hat{\rho}_{a} \hat{\sigma}_{1 a} \hat{\sigma}_{2 a}\right) /\left[(n+m-2) \hat{\sigma}_{1 c} \hat{\sigma}_{2 c}\right] \text {. }
$$

If $\mu_{2 u}$ and $\mu_{1 a}$ are respectively the true but unknown values of the means of the unaffected and affected periods at the second and first stations, then the exponent of (6) may be written as

$$
\begin{aligned}
T_{1}^{2}= & {\left[1 /\left(1-\hat{\rho}_{c}^{2}\right)\right]\left\{\left[\left(\hat{\mu}_{1 a}-\hat{\mu}_{1 u}-\delta_{a}\right) / \hat{\sigma}_{1 c}\right]^{2}-\right.} \\
& -2 \hat{\rho}_{c}\left[\left(\hat{\mu}_{1 a}-\hat{\mu}_{1 u}-\delta_{a}\right) / \hat{\sigma}_{1 c}\right]\left[\left(\hat{\mu}_{2 a}-\hat{\mu}_{2 u}-\delta_{u}\right) / \hat{\sigma}_{2 c}\right]+ \\
& \left.+\left[\left(\hat{\mu}_{2 a}-\hat{\mu}_{2 u}-\delta_{u}\right) / \hat{\sigma}_{2 c}\right]^{2}\right\} .
\end{aligned}
$$

The statistic $T_{1}^{2}$ is the Hotelling's $T^{2}$, and is distributed as an $F$-statistic with 2 and $N-3$ degrees of freedom as in (16) where $N$ is the total number of observations $(=m+n)$.

$$
T^{2}=2\{(N-2) /(N-3)\} F(2, N-3) .
$$

The differences in the population mean values of data from the affected and unaffected periods in the station $2, \delta_{u}$, is by definition equal to zero. Also according to the null hypothesis, $\delta_{a}$ is equal to 0 . In view of these considerations, $\delta_{u}$ and $\delta_{a}$ are set equal to zero (in (15)) and the test statistic is computed. The decision rule for the test is given below:

$$
\text { If }\left(T_{1}^{2} / 2\right)\{(N-3) /(N-2)\} \quad\left\{\begin{array}{l}
\geqslant F_{1-2 \alpha}(2, N-3) \rightarrow \text { reject } H_{0} \\
<F_{1-2 \alpha}(2, N-3) \rightarrow \text { accept } H_{0}
\end{array}\right.
$$

$T^{2}$ test no. 2-test using covariance estimators from the unaffected period: Instead of using $\hat{\rho}_{c}$ in (15), the $T^{2}$-statistic can be defined by using the estimate of the unaffected period correlation coefficient $\hat{\rho}_{u}$ as shown below

$$
\begin{aligned}
T_{2}^{2}= & {[n(m-1) / N]\left[1 /\left(1-\hat{\rho}_{u}^{2}\right)\right]\left\{\left[\left(\hat{\mu}_{1 a}-\hat{\mu}_{1 u}\right) / \hat{\sigma}_{1 u}\right]^{2}-\right.} \\
& \left.-2 \hat{\rho}\left[\left(\hat{\mu}_{1 a}-\hat{\mu}_{1 u}\right) / \hat{\sigma}_{1 u}\right]\left[\left(\hat{\mu}_{2 a}-\hat{\mu}_{2 u}\right) / \hat{\sigma}_{2 u}\right]+\left[\left(\hat{\mu}_{2 a}-\hat{\mu}_{2 u}\right) / \hat{\sigma}_{2 u}\right]^{2}\right\} .
\end{aligned}
$$

The adjusted $T_{2}^{2}$ statistic in (17) is $F$-distributed with 2 and $N$-2 degrees of freedom as given below

$$
\left(T_{2}^{2} / 2\right)\{(m-2) /(m-1)\}=F(2, m-2) .
$$

The decision rule for this test is given below.

$$
\text { If } \frac{T_{2}^{2}}{2}\left\{\frac{m-2}{m-1}\right\}\left[\begin{array}{l}
\geqslant F_{1-2 \alpha}(2, m-2) \rightarrow \text { reject } H_{0} \\
<F_{1-2 \alpha}(2, m-2) \rightarrow \text { accept } H_{0}
\end{array}\right.
$$

$T^{2}$ test no. 3-test using covariance estimators from the affected period: The $T_{3}^{2}$ statistic used in this case is similar to the $T_{2}^{2}$-statistic with the exception that the affected period correlation coefficient $\hat{\rho}_{a}$ is used. The $T_{3}^{2}$-statistic is given by

$$
\begin{aligned}
T_{3}^{2}= & {[m(n-1) / N]\left[1 /\left(1-\hat{\rho}_{a}^{2}\right)\right]\left\{\left[\left(\hat{\mu}_{1 a}-\hat{\mu}_{1 u}\right) / \hat{\sigma}_{1 a}\right]^{2}-\right.} \\
& \left.-2 \hat{\rho}_{a}\left[\left(\hat{\mu}_{1 a}-\hat{\mu}_{1 u}\right) / \hat{\sigma}_{1 a}\right]\left[\left(\hat{\mu}_{2 a}-\hat{\mu}_{2 u}\right) / \hat{\sigma}_{2 a}\right]+\left[\left(\hat{\mu}_{2 a}-\hat{\mu}_{2 u}\right) / \hat{\sigma}_{2 a}\right]^{2}\right\} .
\end{aligned}
$$


The adjusted $T_{3}^{2}$ statistic is $F$-distributed with 2 and $N-2$ degrees of freedom. The decision rule is as follows.

$$
\text { If } \frac{T_{3}^{2}}{2}\left[\frac{n-2}{n-1}\right]\left[\begin{array}{l}
\geqslant F_{1-2 \alpha}(2, n-2) \rightarrow \text { reject } H_{0} \\
<F_{1-2 \alpha}(2, n-2) \rightarrow \text { accept } H_{0} .
\end{array}\right.
$$

The results of $T^{2}$ tests and the decisions are given in table 4. Data from several unaffected stations are used with those from affected stations. However, the results obtained from affected and unaffected stations which are best correlated and the mean value of the unaffected station that has practically remained the same in the affected and unaffected periods are the most reliable. With these points in view and arguing similarly as in the discussion of results of the $\chi^{2}$-test, the following conclusions may be drawn from the $T^{2}$-test.

The null hypothesis $\left(H_{0}\right)$ is rejected for LaPorte, Valley Park, and Kansas City and accepted for all other stations when $T^{2}$-test no. 1 or 3 is conducted by using (1) pooled estimators and (2) estimators from the affected period. But with the $T^{2}$-test no. 2 in which estimators from the unaffected period are used, none of the stations including LaPorte show any significant change in the mean value. Since the unaffected period is short (14 years for LaPorte, 15 years for Tulsa etc.), the results obtained by the $T^{2}$-test no. 2 are not reliable. These results are included in table 4 only for completeness.

Table 4. Results from the $T^{2}$-test

\begin{tabular}{|c|c|c|c|c|c|c|c|c|c|c|}
\hline \multirow[b]{2}{*}{ Station 1} & \multirow[b]{2}{*}{ Station 2} & \multicolumn{3}{|c|}{ Test number 1} & \multicolumn{3}{|c|}{ Test number 2} & \multicolumn{3}{|c|}{ Test number 3} \\
\hline & & $\begin{array}{c}\text { Test } \\
\text { statistic }\end{array}$ & $\begin{array}{l}\text { Critical } \\
\text { value }\end{array}$ & $\begin{array}{l}\text { Deci- } \\
\text { sion }\end{array}$ & $\begin{array}{c}\text { Test } \\
\text { statistic }\end{array}$ & $\begin{array}{c}\text { Critical } \\
\text { value }\end{array}$ & $\begin{array}{l}\text { Deci- } \\
\text { sion }\end{array}$ & $\begin{array}{c}\text { Test } \\
\text { statistic }\end{array}$ & $\begin{array}{c}\text { Critical } \\
\text { value }\end{array}$ & $\begin{array}{l}\text { Deci- } \\
\text { sion }\end{array}$ \\
\hline LAP & SB & 8.0193 & $2 \cdot 42$ & $\mathbf{R}$ & $0-9046$ & $3 \cdot 11$ & $\mathbf{A}$ & $6 \cdot 3148$ & $2 \cdot 44$ & $\mathbf{R}$ \\
\hline LAP & VALP & $7 \cdot 2155$ & $2 \cdot 42$ & $\mathbf{R}$ & $0-2966$ & $3 \cdot 11$ & $\mathbf{A}$ & 6.4354 & $2 \cdot 44$ & $\mathbf{R}$ \\
\hline LAP & PLY & 5.3949 & $2 \cdot 42$ & $\mathbf{R}$ & 0.2867 & $3 \cdot 11$ & $\mathbf{A}$ & $4 \cdot 6261$ & $2 \cdot 44$ & $\mathbf{R}$ \\
\hline ST LS & WAR & $0-8641$ & $2 \cdot 40$ & A & 0.0440 & $2 \cdot 55$ & $\mathbf{A}$ & 0.6545 & $2 \cdot 50$ & $\mathbf{A}$ \\
\hline ST LS & VALL & 0.3937 & $2 \cdot 40$ & $\mathbf{A}$ & 0.0151 & $2 \cdot 55$ & $\mathbf{A}$ & 0.3490 & $2 \cdot 50$ & A \\
\hline ST LS & ST CH & 0.4996 & $2 \cdot 40$ & $\mathbf{A}$ & 0.0172 & $2 \cdot 55$ & $\mathbf{A}$ & 0.4894 & $2 \cdot 50$ & $\mathbf{A}$ \\
\hline EDW & WAR & $1 \cdot 7227$ & $2 \cdot 40$ & $\mathbf{A}$ & 0.0928 & $2 \cdot 55$ & $\mathbf{A}$ & 1.2773 & $2 \cdot 50$ & $\mathbf{A}$ \\
\hline EDW & VALL & 0.8223 & $2 \cdot 40$ & $\mathbf{A}$ & 0.0339 & $2 \cdot 55$ & $\mathbf{A}$ & 0.7325 & $2 \cdot 50$ & $\mathbf{A}$ \\
\hline EDW & ST CH & 0.8130 & $2 \cdot 40$ & $\mathbf{A}$ & $0-0296$ & $2 \cdot 55$ & $\mathbf{A}$ & 0.7364 & $2 \cdot 50$ & $\mathbf{A}$ \\
\hline KAN & LEX & 0.9064 & $2 \cdot 37$ & A & 0.0458 & $2 \cdot 47$ & $\mathbf{A}$ & 0.6970 & $2 \cdot 50$ & $\mathbf{A}$ \\
\hline KAN & LAW & $1 \cdot 1836$ & $2 \cdot 37$ & $\mathbf{A}$ & 0.0387 & $2 \cdot 47$ & $\mathbf{A}$ & $1 \cdot 1209$ & $2 \cdot 50$ & A \\
\hline KAN & EDG & 0.5804 & $2 \cdot 37$ & A & 0.5580 & $2 \cdot 47$ & $\mathbf{A}$ & 0.5214 & $2 \cdot 50$ & A \\
\hline KAN & OLA & $4 \cdot 1051$ & $2 \cdot 37$ & $\mathbf{R}$ & 00980 & $2 \cdot 47$ & A & $4 \cdot 2915$ & $2 \cdot 50$ & $\mathbf{R}$ \\
\hline LEAV & LEX & 0.7752 & $2 \cdot 37$ & A & 0.0305 & $2 \cdot 45$ & A & 0.6665 & 2.50 & A \\
\hline LEAV & LEX & 1.0686 & $2 \cdot 37$ & A & 0.0324 & 2.45 & $\mathbf{A}$ & $1 \cdot 1182$ & $2 \cdot 50$ & A \\
\hline LEAV & EDG & 1.9034 & $2 \cdot 37$ & $\mathbf{A}$ & $2 \cdot 2750$ & 2.45 & $\mathbf{A}$ & 0.7595 & 2.50 & A \\
\hline LEAV & OLA & 0.3373 & $2 \cdot 37$ & $\mathbf{A}$ & 0.0175 & $2 \cdot 45$ & $\mathbf{A}$ & 0.2631 & $2 \cdot 50$ & $\mathbf{A}$ \\
\hline TULS & CLA & 0.6672 & $2 \cdot 40$ & $\mathbf{A}$ & 0.0188 & $2 \cdot 76$ & $\mathbf{A}$ & 0.6666 & $2 \cdot 45$ & $\mathbf{A}$ \\
\hline TULS & CLE & 0.5264 & $2 \cdot 40$ & $\mathbf{A}$ & $0-0124$ & $2 \cdot 76$ & A. & 0.5232 & 2.45 & $\mathbf{A}$ \\
\hline TULS & MUS & 1.4005 & $2 \cdot 40$ & $\mathbf{A}$ & 0.0290 & $2 \cdot 76$ & $\mathbf{A}$ & 0.6344 & 2.45 & $\mathbf{A}$ \\
\hline VALL & WAR & $4 \cdot 4643$ & $2 \cdot 40$ & $\mathbf{R}$ & $2 \cdot 2250$ & 2.55 & A & $2 \cdot 7859$ & $2 \cdot 50$ & $\mathbf{R}$ \\
\hline VALL & ST CH & 1.5589 & $2 \cdot 40$ & $\mathbf{A}$ & 0.7230 & 2.55 & $\mathbf{A}$ & 0.6447 & $2 \cdot 50$ & $\mathbf{A}$ \\
\hline
\end{tabular}

$A$-accept that there is no change in mean; $\mathbf{R}$-reject that there is no change in mean. Abbreviations as in table 1. 
(c) The likelihood ratio-test

The likelihood ratio test is based upon the conditional distribution of annual precipitation. Let $f_{i}$ and $f_{j}$ respectively denote the conditional distributions of the annual rainfall at station 1 for the unaffected and affected periods, conditioned upon the annual rainfall at station 2 of the corresponding periods.

$$
\begin{aligned}
& f_{i}=f\left(P_{1 u i} \mid P_{2 u i} ; \mu_{1 u}, \mu_{2 u}, \sigma_{1 u}^{2}, \sigma_{2 u}^{2}, \rho_{u}\right), \\
& f_{j}=f\left(P_{1 a u} \mid P_{2 a j} ; \mu_{1 u}+\delta, \mu_{2 u}, \sigma_{1 u}^{2}, \sigma_{2 u}^{2}, \rho_{u}\right) .
\end{aligned}
$$

The joint bivariate normal distribution function of the unaffected and affected period annual rainfall is given by

$$
\begin{aligned}
\prod_{i=1}^{m} f_{i} \prod_{j=1}^{n} f_{j}= & \prod_{i=1}^{m}\left(P_{1 u i} \mid P_{2 u i} ; \mu_{1 u}, \mu_{2 u}, \sigma_{1 u}^{2}, \sigma_{2 u}^{2}, \rho_{u}\right), \\
& \prod_{j=1}^{n}\left(P_{1 a j} \mid P_{2 a j} ; \mu_{1 u}+\delta, \mu_{2 u}, \sigma_{1 u}^{2}, \sigma_{2 u}^{2}, \rho_{u}\right)
\end{aligned}
$$

The null and alternate hypotheses for the likelihood ratio test are given below:

$H_{0}: \delta=0$, the change in precipitation mean at station 1 is zero,

$H_{a}: \quad \delta \neq 0$, the change in precipitation mean at station 1 is not zero.

The likelihood ratio applicable to test the null hypothesis is designated $\lambda$ and is given below in (21).

$$
\begin{aligned}
\lambda= & {\left[\prod_{i=1}^{m} f_{i} \prod_{j=1}^{n} f\left(P_{1 a j} \mid P_{2 a j} ; \mu_{1 u}-\beta_{12} \mu_{2 u}, \beta_{12}, \hat{\sigma}_{12}\right)\right] \div } \\
& \div\left[\prod_{i=1}^{m} f_{i} \prod_{j=1}^{n} f(P_{1 a j} \mid P_{2 a j} ; \overbrace{1 u}-\beta_{12} \mu_{2}, \hat{\delta}_{1}, \hat{\beta}_{12}, \hat{\sigma}_{12})\right] .
\end{aligned}
$$

In (21) the estimates denoted by ^ are maximum likelihood estimators with $\delta=0$ and those denoted by ${ }^{*}$ are estimators computed with unknown $\delta$ values. $\beta_{12}$ is the regression coefficient. The statistic $\lambda$ has been shown to be (Graybill 1961) the same as, under the normal distribution and other assumptions, the ratio of adjusted regression sum of squares to the sum of squares of residuals. The square root of absolute value of the likelihood ratio can be shown to be the statistic $t_{\lambda}$ given below.

$$
\begin{aligned}
t_{\lambda}= & \frac{\sum_{i=1}^{m}\left(P_{2 u i}-\hat{\mu}_{2 u}\right)\left(P_{1 u i}\right)+\sum_{j=1}^{n}\left(P_{2 a j}-\hat{\mu}_{2 a}\right) P_{1 a j}}{\left[\sum_{i=1}^{m}\left(P_{2 u i}-\hat{\mu}_{2 u}\right)^{2}+\sum_{j=1}^{n}\left(P_{2 a j}-\hat{\mu}_{2 a}\right)^{2}\right]^{\frac{1}{2}}\left(\hat{\mu}_{2 a}-\hat{\mu}_{2 u}\right)} \\
& \times \sum_{i=1}^{m}\left(P_{1 u i}-\hat{\mu}_{1 u}\right)^{2}+\sum_{j=1}^{n}\left(P_{1 a j}-\hat{\mu}_{1 a}\right)^{2} \frac{\sum_{i=1}^{m}\left(P_{2 u i}-\hat{\mu}_{2 u}\right) P_{1 u i}-\sum_{j=1}^{n}\left(P_{2 a j}-\hat{\mu}_{2 a}\right) P_{1 a j}}{\sum_{i=1}^{m}\left(P_{2 u i}-\hat{\mu}_{2 u}\right)^{2}+\sum_{j=1}^{n}\left(P_{2 a j}-\hat{\mu}_{2 a}\right)^{2}} \\
& \times\left[\frac{N}{n m}+\frac{\left(\hat{\mu}_{2 a}-\hat{\mu}_{2 u}\right)^{2}}{\sum_{i=1}^{m}\left(P_{2 u i}-\hat{\mu}_{2 u}\right)^{2}+\sum_{j=1}^{n}\left(P_{2 a j}-\hat{\mu}_{2 a}\right)^{2}}\right]^{-\frac{1}{2}}
\end{aligned}
$$


The statistic $t_{\lambda}$ is a $t$-like statistic and has a $t$-distribution with $(N-3)$ degrees of freedom. The decision rule for the test is given below.

$$
\text { If } t_{\lambda} \begin{cases}\leqslant t_{1-\alpha}(N-3) \rightarrow & \begin{array}{l}
\text { accept the null hypothesis that the } \\
\text { change in the mean at station } 1 \text { is } \\
\text { not significantly different from zero. }
\end{array} \\
>t_{1-\alpha}(N-3) \rightarrow & \text { reject the null hypothesis. }\end{cases}
$$

The results of the likelihood ratio test, which are given in table 5 are generally similar to those from the $T^{2}$-test but with some significant differences. The change in the mean values at LaPorte, Valley Park, Edwardsville, and Kansas City, according to the likelihood ratio test is significant whereas it is not significant at the other stations.

\section{(d) The conditional-t test}

In this test, which is discussed in detail by Markovic (1966), the joint distribution of the annual precipitation in the affected and unaffected stations in the affected period is developed by using the sample statistics. The population means of the data from the affected (first) and unaffected (second) stations are denoted by $\mu_{a}$ and $\mu_{u}$. The precipitation from the affected and unaffected stations are assumed to be normally distributed and the joint distribution to be bivariate normal with parameter $\rho$.

Table 5. Results from likelihood-ratio test

\begin{tabular}{|c|c|c|c|c|}
\hline Station 1 & Station 2 & $\begin{array}{c}\text { Test } \\
\text { statistic }\end{array}$ & $\begin{array}{c}\text { Critical } \\
\text { value }\end{array}$ & Decision \\
\hline LAP & SB & 3.9863 & 1.68 & $\mathbf{R}$ \\
\hline LAP & VALP & 3.6988 & 1.68 & $\mathbf{R}$ \\
\hline LAP & PLY & $2 \cdot 7048$ & 1.68 & $\mathbf{R}$ \\
\hline ST LS & WAR & $1 \cdot 3031$ & 1.69 & $\mathbf{A}$ \\
\hline ST LS & VALL & 0.4262 & 1.69 & A \\
\hline ST LS & ST CH & -0.0210 & 1.69 & $\mathbf{A}$ \\
\hline EDW & WAR & 1.8478 & 1.69 & $\mathbf{R}$ \\
\hline EDW & VALL & 1.0144 & 1.69 & $\mathbf{A}$ \\
\hline EDW & ST CH & 0.7844 & $1 \cdot 69$ & A \\
\hline KAN & LEX & -1.3383 & 1.67 & A \\
\hline KAN & LAW & -1.5381 & 1.67 & $\mathbf{A}$ \\
\hline KAN & EDG & -0.5294 & 1.67 & A \\
\hline KAN & OLA & -2.8050 & 1.67 & $\mathbf{R}$ \\
\hline LEAV & LAW & 1.4614 & 1.67 & A \\
\hline LEAV & EDG & $0-9275$ & 1.67 & $\mathbf{A}$ \\
\hline LEAV & OLA & 0.6084 & 1.67 & $\mathbf{A}$ \\
\hline LEAV & LEX & $1 \cdot 2364$ & 1.67 & A \\
\hline TULS & CLA & -0.2923 & 1.69 & $\mathbf{A}$ \\
\hline TULS & CLE & -0.8077 & 1.69 & $\mathbf{A}$ \\
\hline TULS & MUS & $-1 \cdot 1693$ & 1.69 & A \\
\hline VALL & WAR & 2.0412 & 1.69 & $\mathbf{R}$ \\
\hline VALL & ST CH & $0-7216$ & 1.69 & A \\
\hline
\end{tabular}

$A-$ accept the null hypothesis that there is no change in the mean; $\mathbf{R}$-reject the null hypothesis that there is no change in the mean. Abbreviations as in table 1. 
All the above distributions are postulated under the assumption that the precipitation mean in the affected station has not significantly changed. The null and alternate hypotheses for the test are as follows:

$H_{0}$ : There is no significant change in the precipitation mean in the affected station.

$H_{a}$ : There is a significant change.

The test procedure is as follows. The observed affected and unaffected t-statistics under the null hypothesis are computed as follows

$$
\begin{aligned}
& t_{a}=\left[\left(\hat{\mu}_{1 a}-\hat{\mu}_{1 u}\right) / \hat{\sigma}_{1 a}\right](n-1)^{\frac{1}{2}} \quad \text { (first station), } \\
& t_{u}=\left[\left(\hat{\mu}_{2 a}-\hat{\mu}_{2 u}\right) / \hat{\sigma}_{2 a}\right](n-1)^{\frac{1}{2}} \quad \text { (second station). }
\end{aligned}
$$

The means of the conditional affected-unaffected distribution function is computed as follows, where $\Gamma($.$) is the gamma function.$

$$
\begin{aligned}
& E\left(t_{a} \mid t_{u} ; \rho\right)=A_{1} B_{1}, \\
& A_{1}=\frac{\left(1-\rho^{2}\right)^{n / 2}}{\Pi^{\frac{1}{2}} \Gamma[n / 2]} \\
& B_{1}=\sum_{k=0}^{\infty} \sum_{\lambda=0}^{\infty} \frac{\rho^{2 k}}{k ! \Gamma\{[(n-1) / 2]+k\}} \cdot \frac{\left(2 \rho t_{u}\right)^{2 \lambda+1}}{(2 \lambda+1) !(n-1)^{\lambda}} C_{1} ; \\
& C_{1}=\frac{\Gamma[(n+1) / 2]+k+\lambda}{\left\{\left[t_{u}^{2} /(n-1)\right]+1\right\}^{1 / 2+k+\lambda}} \cdot \Gamma\{[(n-2) / 2]+k\} \Gamma[(3 / 2)+\lambda] .
\end{aligned}
$$

The conditional variance of the affected-unaffected distribution function is given by

$$
\begin{aligned}
& \operatorname{Var}\left(t_{a} \mid t_{u} ; \rho\right)=E\left[\left(t_{a} \mid t_{u} ; \rho\right)^{2}\right]-E\left(t_{a} \mid t_{u} ; \rho\right)^{2} \\
& E\left[\left(t_{a} \mid t_{u} ; \rho\right)^{2}\right]=\frac{2(n-1)\left(1-\rho^{2}\right)^{n / 2}}{\pi^{\frac{1}{2}} \Gamma[n / 2]} \sum_{k=0}^{\infty} \sum_{\lambda=0}^{\infty} \frac{\rho^{2 k}}{k !(n-3+2 k)} \cdot \frac{\left(2 \rho t_{u}\right)^{2 \lambda}}{(2 \lambda) !(n-1)^{\lambda}} A_{2}, \\
& A_{2}=\frac{\Gamma[(n / 2)+k+\lambda]}{\left\{\left[t_{u}^{2} /(n-1)\right]+1\right\}^{k+\lambda}} \Gamma|(3 / 2)+\lambda|
\end{aligned}
$$

The critical value of $t_{a}$ given $t_{u}$, and $\hat{\rho}$ at the level of significance $\alpha$ is given by

$$
\left[t_{a} \mid t_{u} ; \rho\right]_{1-\alpha}=[t(n-1)]_{1-\alpha}[(n-3) /(n-1)]\left[\operatorname{Var}\left(t_{a} \mid t_{u} ; \hat{\rho}\right)\right]^{1 / 2},
$$

where $[t(n-1)]_{1-\alpha}$ is the critical value of $t_{a}$ at the level of significance $1-\alpha$, with $(n-1)$ degrees of freedom. The decision rule for the test is given below.

$$
\text { If }\left\{t_{a}-E\left(t_{a} \mid t_{u} ; \rho\right)\right\} \quad\left[\begin{array}{l}
<\left(t_{a} \mid t_{u} ; \rho\right)_{1-\alpha} \rightarrow \text { accept } H_{0}, \\
\geqslant\left(t_{a} \mid t_{u} ; \rho\right)_{1-\alpha} \rightarrow \text { reject } H_{0} .
\end{array}\right.
$$

Acceptance of the null hypothesis means that the change in the precipitation mean value in the affected station is not significantly different from zero. The computational procedure is as follows.

The observed affected and unaffected $t$ statistics, $t_{a}$ and $t_{u}$, under the null hypothesis are computed by using (23) and the mean of the conditional affected- 
unaffected distribution function is computed by (24). In computing $E\left(t_{a} \mid t_{\mu} ; \rho\right)$ in (24) and $E\left[\left(t_{a} \mid t_{u} ; \rho\right)^{2}\right]$ in (26), the first summation on $k$ is limited to 200 and the second summation on $\lambda$ is limited to 15 . The critical value of the test statistic $\left(t_{a} \mid t_{u} ; \rho\right)$ is computed by using (25) and (27). It is emphasized again that the test gives the best results for a pair of affected-unaffected stations for which the correlation coefficient is maximum and the mean value of the unaffected station has not changed very much.

The results of the conditional $t$-test are summarized in table 6 . The null hypothesis is rejected for LaPorte for all station-pair combinations, and for the St. LouisWarrenton data. Since the correlation coefficient between St. Louis and Warrenton is $\mathbf{0 . 7 5 3}$, the result obtained by using the St. Louis-Warrenton pair can be considered reliable. The null hypothesis is rejected for the Edwardsville-Warrenton data which indicates an increase at Edwardsville. Thus, we can conclude that there is an increase in the observed precipitation mean value at Edwardsville.

The test indicates a decrease in observed mean precipitation at Kansas City for any combination of stations. The null hypothesis is accepted for Leavenworth data indicating no significant change. The result for Tulsa indicates a decrease in the affected period precipitation although observed mean value has increased at Tulsa. Therefore the results for Tulsa are suspect.

\section{Discussion and conclusions}

The results of various tests are summarized in table 7. The tests were performed at a $5 \%$ significance level. However, test results with a $1 \%$ significance level did not indicate any substantial differences from those obtained by using the $5 \%$ level. The

Table 6. Results from the conditional t test

\begin{tabular}{|c|c|c|c|c|c|c|c|c|}
\hline Station 1 & Station 2 & $\hat{\boldsymbol{\rho}}$ & $t_{w}$ & $E\left[t_{a} \mid t_{w} ; \rho\right]^{2}$ & $E\left[t_{a} \mid t_{u} ; \rho\right]$ & $\begin{array}{c}\text { Test } \\
\text { statistic }\end{array}$ & $\begin{array}{c}\text { Critical } \\
\text { value }\end{array}$ & $\begin{array}{l}\text { Deci- } \\
\text { sion }\end{array}$ \\
\hline LAP & SB & 0.806 & $3 \cdot 366$ & $1 \cdot 119$ & $2 \cdot 289$ & 4.902 & 1.685 & $\mathbf{R}$ \\
\hline LAP & PLY & 0.648 & 1.590 & 1.028 & 1.694 & 4.993 & $1 \cdot 321$ & $\mathbf{R}$ \\
\hline LAP & VALP & 0.893 & 0.678 & 0.608 & 0.583 & 5.415 & 0.765 & $\mathbf{R}$ \\
\hline ST LS & VALL & $0-899$ & 1.108 & 0.989 & $1 \cdot 184$ & 0.261 & 0.745 & $\mathbf{A}$ \\
\hline ST LS & WAR & 0.753 & $-0 \cdot 270$ & 0.270 & 0.499 & 1.456 & $1 \cdot 109$ & $\mathbf{R}$ \\
\hline ST LS & ST CH & 0.872 & 1.474 & $1 \cdot 241$ & 1.801 & 0.008 & 0.836 & $\mathbf{A}$ \\
\hline EDW & VALL & 0.839 & $1 \cdot 1088$ & 0.933 & $1 \cdot 100$ & 0.893 & 0.939 & $\mathbf{A}$ \\
\hline EDW & WAR & 0.788 & -0.270 & -0.216 & 0.445 & 2.043 & 1.036 & $\mathbf{R}$ \\
\hline EDW & ST CH & 0.823 & 1.474 & 1.208 & 1.824 & 0.618 & 0.990 & $\mathbf{A}$ \\
\hline KAN & LAW & 0.673 & -0.055 & -0.037 & 0.572 & $-1 \cdot 307$ & $1 \cdot 251$ & $\mathbf{R}$ \\
\hline KAN & LEX & 0.776 & -0.221 & -0.173 & 0.431 & $-1 \cdot 172$ & 1.064 & $\mathbf{R}$ \\
\hline KAN & OLA & 0.736 & 0.806 & 0.598 & 0.842 & -1.943 & $1 \cdot 152$ & $\mathbf{R}$ \\
\hline LEA & LAW & 0.570 & -0.221 & -0.128 & 0.722 & 1.258 & $1 \cdot 391$ & $\mathbf{A}$ \\
\hline LEA & LEX & 0.659 & -0.055 & -0.037 & 0.590 & $1 \cdot 166$ & $1 \cdot 270$ & $\mathbf{A}$ \\
\hline LEA & OLA & 0.574 & 0.806 & 0.468 & 0.928 & 0.661 & $1 \cdot 393$ & $\mathbf{A}$ \\
\hline TULS & CLA & 0.907 & $-2 \cdot 111$ & -0.596 & 0.840 & -1.381 & $1 \cdot 154$ & $\mathbf{R}$ \\
\hline TULS & CLE & 0.714 & -1.173 & -0.841 & $1 \cdot 236$ & $-1 \cdot 136$ & 1.204 & $\mathbf{A}$ \\
\hline TULS & MUS & 0.798 & $-0 \cdot 147$ & -0.118 & 0.391 & -1.859 & 1.017 & $\mathbf{R}$ \\
\hline
\end{tabular}

A-accept the null hypothesis that there is no change in the mean;

$\mathrm{R}$-reject the null hypothesis that there is no change in the mean;

$\hat{\rho}$-correlation coefficient.

Abbreviations as in table 1. 
Table 7. Summary of results

\begin{tabular}{|c|c|c|c|c|c|c|}
\hline \multirow[b]{3}{*}{ Station } & \multirow[b]{3}{*}{$\begin{array}{c}\chi^{2} \\
\text { Test }\end{array}$} & \multicolumn{5}{|c|}{ Bivariate tests } \\
\hline & & \multicolumn{3}{|c|}{$T^{2}$ test } & \multirow[b]{2}{*}{$\begin{array}{c}\text { LHR } \\
\text { test }\end{array}$} & \multirow[b]{2}{*}{$\begin{array}{c}\text { Conditiona } \\
\text { t-test }\end{array}$} \\
\hline & & $\begin{array}{c}\text { Test } \\
\text { no. } 1\end{array}$ & $\begin{array}{c}\text { Test } \\
\text { no. } 2\end{array}$ & $\begin{array}{c}\text { Test } \\
\text { no. } 3\end{array}$ & & \\
\hline LAP & $\mathbf{R}$ & $\mathbf{R}$ & $\mathbf{A}$ & $\mathbf{R}$ & $\mathbf{R}$ & $\mathbf{R}$ \\
\hline ST LS & $\mathbf{R}$ & A & A & $\mathbf{A}$ & $\mathbf{A}$ & $\mathbf{R}$ \\
\hline EDW & $\mathbf{R}$ & $\mathbf{A}$ & $\mathbf{A}$ & $\mathbf{A}$ & $\mathbf{R}$ & $\mathbf{R}$ \\
\hline VALL & $\mathbf{R}$ & $\mathbf{R}$ & $\mathbf{A}$ & $\mathbf{R}$ & $\mathbf{R}$ & $\mathbf{R}$ \\
\hline KAN & $\mathbf{R}$ & $\mathbf{R}$ & $\mathbf{A}$ & $\mathbf{R}$ & $\mathbf{A}$ & $\mathbf{R}$ \\
\hline LEAV & $\mathbf{R}$ & $\mathbf{A}$ & A & $\mathbf{A}$ & $\mathbf{R}$ & $\mathbf{A}$ \\
\hline TULS & $\mathbf{R}$ & A & $\mathbf{A}$ & $\mathbf{A}$ & $\mathbf{A}$ & $\mathbf{R}^{*}$ \\
\hline
\end{tabular}

A-accept the hypothesis that there is no change in the mean

$\mathbf{R}$-reject the hypothesis that there is no change in the mean

LHR - likelihood ratio; $\mathbf{R}^{*}$-result suspect.

following observations can be made about the significance of the observed changes in these stations.

(i) All the tests except for $T^{2}$-test no. 2 indicate the observed change in precipitation at LaPorte to be clearly significant.

(ii) The $\chi^{2}$ - and conditional $t$-tests indicate that the observed increase in the mean precipitation at St. Louis is significant. The $\chi^{2}-$, the likelihood ratio and the conditional $t$-tests indicate significant increases at Edwardsville. All the tests except $T^{2}$-test no. 1 indicate that the observed increase at Valley Park is significant.

(iii) The observed decrease in precipitation mean at Kansas City is significant as indicated by the $\chi^{2}$-test, $T^{2}$-tests 1 and 3 and conditional $t$-tests. The change in precipitation mean at Leavenworth is significant as indicated by the $\chi^{2}$ and likelihood ratio tests.

(iv) The observed increase in affected period precipitation at Tulsa is found to be significant as indicated by the results obtained by the $\chi^{2}-$, and the conditional $t$-tests, but the conditional $t$-test results are suspect as mentioned earlier.

It is important to point out that different tests give different results for the data from a station. This is due to the assumptions made in the tests and also due to the fact that the observed change may be only marginally significant. The following general comments are valid in accepting the conclusions presented above.

(i) The $\chi^{2}$-test assumes that the population parameters are known, whereas the $T^{2}$ test assumes that the population parameters are unknown. Since these parameters are not accurately known, especially for sample sizes, the $T^{2}$-test is better than the $\chi^{2}$ test. The three variants of the $T^{2}$-test enable us to interpret the results correctly depending upon the available sample size in the affected, unaffected and the entire periods. However, it is believed that the $T^{2}$-test 3 is more reliable than the $T^{2}$-test 1 or the $T^{2}$-test 2, because the $T^{2}$-test 1 uses statistics which are based on the affected period data. The number of samples in the affected period is generally large in comparison with the number of samples in the unaffected period for most of the stations used in the present analysis.

(ii) The likelihood ratio test and the conditional $t$ tests are the most powerful among 
the several tests considered in this study. This is particularly true when we are dealing with moderate or large samples in the affected period, and when the unaffected and affected period variances differ very much. In the present study, the affected period sample size is larger than that of the unaffected period for most of the stations, and hence better estimates of the unknown population variances are available. Although the conditional $t$-test is the most complex among the tests considered, the results obtained from this test are most convincing according to the results obtained herein and also according to the results of Markovic (1966).

In view of these general considerations, it may be concluded that the $T^{2}$-test 1 , likelihood ratio and conditional $t$-tests are the more powerful tests for determining the significance of changes in rainfall in the urban areas considered in this study. According to these tests the mean annual precipitation has significantly changed at LaPorte, Valley Park, Kansas City, Leavenworth, St. Louis and Edwardsville. The results at Tulsa are suspect. The observed changes at all other stations used in this study are not significant.

\section{References}

Ackerman B S, Changnon S A Jr, Dzurisin G, Gatz D F, Grosh R C, Hilberg S D, Huff F A, Mansell J W, Ochs H T, Peden M E, Schickdanz P T, Semonin R G, Vogel J L 1978 Summary of METROMEX.,Vol. 2, Causes of precipitation anomalies, Illinois State Water Survey Bulletin no. 63, Urbana

Brownlee K A 1965 Statistical theory and methodologies in engineering (New York: John Wiley and Sons) Changnon S A Jr 1968 Bull. Am. Meteorol. Soc. 49: 4-11

Changnon S A Jr 1969 Bull. Am. Meteorol. Soc. 50: 411-421

Changnon S A Jr 1973 J. Irrig. Drain. Div., Am. Soc. Civil. Eng. 99: 27-41

Changnon S A Jr 1980 Bull. Am. Meterol. Soc. 61: 702-711

Changnon S A Jr (ed.) 1981 Metromex: A review and summary, Am. Meterol. Soc., vol. 18, Monograph No. 40

Changnon S A Jr, Huff F A, Schickedanz P T, Vogel J L 1977 Summary of METROMEX, Vol. 1, Anomalies and impacts, Illinois State Water Survey Bulletin no. 62, Urbana

Changnon S A Jr, Jameson A R, Dzurisin G L, Scott R W, Grosh R C 1979 Studies of urban and lake influences on precipitation in the Chicago Area, Illinois State Water Survey, Urbana

Graybill F A 1961 An introduction to linear statistical models (New York: McGraw-Hill)

Hald A 1952 Statistical theory with engineering applications (New York: John Wiley and Sons)

Huff F A, Changnon S A Jr 1970 Urban effects on daily rainfall distributions, Preprints of Papers presented at the Am. Met. Soc. 11 National Conference on Weather Modification, Santa Barbara, California, pp. 215-220

Landsberg H E 1970a Science 170: 1265-1274

Landsberg H E 1970b In Urban climates (see World Meteorol. Organisation 1970b) pp. 364-374

Markovic R D 1966 Statistical evaluation of weather modification attainments, Hydrology paper No. 16, Colorado State Univ., Fort Collins, Colorado

Mood A M, Graybill F A 1963 Introduction to the theory of statistics (New York: MoGraw Hill)

Rao A R, Rao S G 1974 Analysis of the effect of urbanization on rainfall characteristics -I, Tech. Rep. No. 50, Water Resources Research Center, Purdue University, West Lafayette, Indiana 